\title{
The Mediterranean diet protects against waist circumference enlargement in 12Ala carriers for the PPAR $\gamma$ gene: 2 years' follow-up of 774 subjects at high cardiovascular risk
}

\author{
Cristina Razquin ${ }^{1}$, J. Alfredo Martinez ${ }^{1}$, Miguel A. Martinez-Gonzalez ${ }^{2}$, Dolores Corella ${ }^{3}$, \\ José Manuel Santos ${ }^{4}$ and Amelia Marti ${ }^{1 *}$ \\ ${ }^{1}$ Department of Nutrition and Food Sciences, Physiology and Toxicology, University of Navarra, Irunlarrea 1, 31080 Pamplona, \\ Navarra, Spain \\ ${ }^{2}$ Department of Preventive Medicine and Public Health, School of Medicine-Clinica Universitaria, University of Navarra, Spain \\ ${ }^{3}$ Department of Preventive Medicine, School of Medicine, University of Valencia, Spain \\ ${ }^{4}$ Department of Family Medicine, San Pablo Health Centre and CIBER Fisiopatología Obesidad y Nutrición (CB06/03), Instituto \\ de Salud Carlos III, Spain \\ (Received 19 September 2008 - Revised 7 January 2009 - Accepted 26 January 2009 - First published online 9 March 2009)
}

\begin{abstract}
The PPAR $y$ gene regulates insulin sensitivity and adipogenesis. The Pro12Ala polymorphism of this gene has been related to fat accumulation. Our aim was to analyse the effects of a 2-year nutritional intervention with Mediterranean-style diets on adiposity in high-cardiovascular risk patients depending on the Pro12Ala polymorphism of the PPAR $\gamma$ gene. The population consisted of a substudy (774 high-risk subjects aged 55-80 years) of the Prevención con Dieta Mediterránea (PREDIMED) randomised trial aimed at assessing the effect of the Mediterranean diet for CVD prevention. There were three nutritional intervention groups: two of them of a Mediterranean-style diet and the third was a control group advised to follow a conventional low-fat diet. All the participants were genotyped by PCR-restriction fragment length polymorphism (RFLP). The results showed that carriers of the 12Ala allele allocated to the control group had a statistically significant higher change in waist circumference (adjusted difference coefficient $=2.37 \mathrm{~cm} ; P=0.014$ ) compared with wild-type subjects after 2 years of nutritional intervention. This adverse effect was not observed among 12Ala carriers allocated to both Mediterranean diet groups. In diabetic patients a statistically significant interaction between Mediterranean diet and the 12Ala allele regarding waist circumference change was observed $(-5 \cdot 85 \mathrm{~cm} ; P=0.003)$. In conclusion, the Mediterranean diet seems to be able to reduce waist circumference in a high-cardiovascular risk population, reversing the negative effect that the 12Ala allele carriers of the PPAR $\gamma$ gene appeared to have. The beneficial effect of this dietary pattern seems to be higher among type 2 diabetic subjects.
\end{abstract}

Genetic epidemiology: Waist circumference: Mediterranean diet: PPAR $\gamma$

CVD, the leading cause of death in developed countries ${ }^{(1,2)}$, is a good example of complex and multifactorial disease caused by genetic, environmental factors and their interactions ${ }^{(3)}$. Excess of adiposity is a major risk factor for CVD, especially when this excess is located in visceral depots ${ }^{(4)}$. The prevention of CVD is currently directed to potential modifiable factors, such as diet and lifestyle factors. In this sense, adiposity indexes (waist circumference and body weight) could be modified by interventions aimed to obtain changes in dietary pattern.

Since the Mediterranean diet was first defined by Keys \& Grande in $1957^{(5)}$, it has been postulated as beneficial against $\mathrm{CVD}^{(6,7)}$ and type 2 diabetes $^{(8)}$. Olive oil consumption, which was the main source of fat (MUFA) in traditional Mediterranean diets, has been widely related to this protective effect $^{(1,7,9,10)}$. Also, tree nuts (a good source of PUFA) are an integral part of the Mediterranean food pattern and previous studies have found a protective association between nut consumption and reduced risk of $\mathrm{CVD}^{(11-13)}$.

One of the most studied genes linked to interactions with dietary compounds is the PPAR $\gamma^{(14-17)}$ that encodes a transcription factor (PPAR $\gamma 2)$ that controls the expression of genes involved in adipocyte differentiation, lipid storage and insulin sensitisation. The effects of the 12Ala allele have been studied in functional analysis, revealing that the receptor carrying this allele displays reduced DNA-binding affinity and impaired transcriptional activity in target genes ${ }^{(18)}$. Therefore the $12 \mathrm{Ala}$ in vivo would be expected to protect against increased adiposity due to the reduced activity of the receptor. However, previous studies in human subjects showed that the 12Ala allele was associated with increased adiposity ${ }^{(19-21)}$. These contradictory results in vitro and in vivo might be 
explained by a potential enhancing effect of the anti-lipolytic action of insulin, which leads to reduced release of $\mathrm{NEFA}^{(18)}$.

The Pro12Ala substitution in this gene has also been widely associated with diabetes ${ }^{(22)}$. Moreover, a positive association between the 12Ala allele of the PPAR $\gamma$ and obesity-related traits was reported among diabetic patients ${ }^{(23)}$.

Most of the associations between diet, risk factors for chronic diseases and genetics have come from observational epidemiological studies and, as with conventional nutrition research, such observations need to be verified by randomised dietary intervention trials to provide the strongest evidence of causality $^{(24)}$. As PPAR $\gamma$ is known to be activated by fatty acids $^{(25)}$, we hypothesised that the effects of a high consumption of virgin olive oil or nuts could be partly explained by means of the effects mediated by PPAR $\gamma$. Thus, our aim was to analyse the effects of a 2-year nutritional intervention with Mediterranean-style diets on adiposity in highcardiovascular risk patients depending on the Pro12Ala polymorphism of the PPAR $\gamma$ gene.

\section{Research methods and procedures}

\section{Study population}

The present study has been conducted within the frame of the Prevención con Dieta Mediterránea (PREDIMED) trial. The design of the PREDIMED trial has been reported in detail elsewhere ${ }^{(1,26)}$. Briefly, the PREDIMED trial is a large, parallel-group, multicentre, randomised and controlled 4-year clinical trial that aims to assess the effects of a Mediterranean-type diet on CVD and in which participants are assigned to one of three different dietary patterns (low-fat diet; Mediterranean diet supplemented with nuts; Mediterranean diet supplemented with virgin olive oil $)^{(1)}$. The study population is composed of men aged 55-80 years and women aged 60-80 years with no previously documented CVD but at high cardiovascular risk. Inclusion criteria were either diabetes mellitus type 2 or at least three of the following risk factors: current smoking, hypertension, hyperlipidaemia, HDL-cholesterol $<1.034 \mathrm{~mm}$, overweight or obesity, or family history of premature CHD.
We included data from 774 participants enrolled in the APUNAV recruitment centre in Pamplona (total number of participants was 1055), in which the retention rate during the second year was greater than $80 \%$. Of the subjects, 141 were excluded for the present study since we were not able to obtain DNA samples or their adiposity measures at year 2 were not recorded. All participants provided informed consent and the protocol was approved by the institutional review boards of all participating centres according to the Declaration of Helsinki.

\section{Dietary assessment}

The dietary habits of the participants, both at baseline and after follow-up for 24 months, were assessed using a semiquantitative 137-item FFQ previously validated in Spain $^{(27)}$. More details about the dietary assessment are described elsewhere ${ }^{(1)}$. We focused the nutritional study on fat intake changes.

\section{Genotyping}

Overnight fasting venous blood samples were collected in tubes containing EDTA. DNA was extracted from the buffy coat fraction using a commercial kit (Master PureTM; Epicentre, Madison, WI, USA). All the subjects were genotyped for the Pro12Ala polymorphism of the PPAR $\gamma$ gene (rs1801282) using the PCR-restriction fragment length polymorphism (RFLP) method as described elsewhere ${ }^{(28)}$.

\section{Statistical analysis}

The $\chi^{2}$ test was used to evaluate the Hardy-Weinberg equilibrium. The Kolmogorov-Smirnov test was used to determine variable distribution. Descriptive analyses of variables between the three intervention groups were performed using parametric tests (Student's $t$ tests; ANOVA followed by Bonferroni post hoc tests). Means of changes in body weight and waist circumference were compared among the three randomised groups and among genotypes using general

Table 1. Baseline characteristics of the participants according to intervention group allocation

(Mean values and standard deviations)

\begin{tabular}{|c|c|c|c|c|c|c|c|c|c|c|c|c|}
\hline & \multicolumn{4}{|c|}{ Control (n 197) } & \multicolumn{4}{|c|}{ Virgin olive oil (n 318) } & \multicolumn{4}{|c|}{ Tree nuts $(n 258)^{\star}$} \\
\hline & \multicolumn{2}{|c|}{$\begin{array}{l}\text { ProPro } \\
\text { (n 168) }\end{array}$} & \multicolumn{2}{|c|}{$\begin{array}{c}\text { 12Ala allele } \\
\text { carriers }\end{array}$} & \multicolumn{2}{|c|}{$\begin{array}{l}\text { ProPro } \\
(n 272)\end{array}$} & \multicolumn{2}{|c|}{$\begin{array}{c}\text { 12Ala allele } \\
\text { carriers }\end{array}$} & \multicolumn{2}{|c|}{$\begin{array}{l}\text { ProPro } \\
(n 221)\end{array}$} & \multicolumn{2}{|c|}{$\begin{array}{c}\text { 12Ala allele } \\
\text { carriers }\end{array}$} \\
\hline & Mean & SD & Mean & SD & Mean & SD & Mean & SD & Mean & SD & Mean & SD \\
\hline Sex (\% female) & \multicolumn{2}{|c|}{$54 \cdot 8$} & \multicolumn{2}{|c|}{$79 \cdot 3$} & \multicolumn{2}{|c|}{$52 \cdot 6$} & \multicolumn{2}{|c|}{$71 \cdot 7$} & \multicolumn{2}{|c|}{$51 \cdot 6$} & \multicolumn{2}{|c|}{45.9} \\
\hline Age (years) & $68 \cdot 0$ & $6 \cdot 9$ & $71 \cdot 6$ & 3.9 & $67 \cdot 8$ & $6 \cdot 7$ & $68 \cdot 7$ & $5 \cdot 8$ & $67 \cdot 5$ & $6 \cdot 8$ & $67 \cdot 7$ & $5 \cdot 6$ \\
\hline Waist:height & 0.6 & 0.1 & 0.6 & 0.1 & 0.6 & 0.1 & 0.6 & 0.1 & 0.6 & 0.1 & 0.6 & 0.1 \\
\hline Waist circumference $(\mathrm{cm})$ & $95 \cdot 2$ & $11 \cdot 6$ & $93 \cdot 9$ & $9 \cdot 9$ & $96 \cdot 6$ & $10 \cdot 5$ & $93 \cdot 1$ & $10 \cdot 4$ & 95.5 & 9.6 & $95 \cdot 8$ & $10 \cdot 2$ \\
\hline Weight $(\mathrm{kg})$ & $74 \cdot 6$ & $12 \cdot 7$ & $72 \cdot 6$ & $10 \cdot 9$ & $76 \cdot 1$ & $12 \cdot 2$ & $73 \cdot 3$ & $10 \cdot 1$ & 74.9 & $10 \cdot 1$ & $75 \cdot 0$ & $11 \cdot 1$ \\
\hline BMI $\left(\mathrm{kg} / \mathrm{m}^{2}\right)$ & $29 \cdot 1$ & 3.5 & $29 \cdot 6$ & $3 \cdot 1$ & $29 \cdot 3$ & $3 \cdot 3$ & $28 \cdot 8$ & $3 \cdot 4$ & $29 \cdot 1$ & $3 \cdot 1$ & $29 \cdot 1$ & $3 \cdot 3$ \\
\hline Systolic blood pressure (mmHg) & $155 \cdot 5$ & $20 \cdot 6$ & $159 \cdot 3$ & $21 \cdot 7$ & $155 \cdot 4$ & $20 \cdot 4$ & 152.9 & $22 \cdot 4$ & $155 \cdot 7$ & $22 \cdot 8$ & $156 \cdot 9$ & 14.4 \\
\hline Diastolic blood pressure (mmHg) & $86 \cdot 2$ & $11 \cdot 0$ & $85 \cdot 0$ & $10 \cdot 0$ & 85.9 & $10 \cdot 5$ & $84 \cdot 7$ & 11.5 & $87 \cdot 5$ & $11 \cdot 1$ & 85.8 & $11 \cdot 2$ \\
\hline Diabetes (\%) & \multicolumn{2}{|c|}{$32 \cdot 1$} & \multicolumn{2}{|c|}{31.0} & \multicolumn{2}{|c|}{34.9} & \multicolumn{2}{|c|}{$45 \cdot 7$} & \multicolumn{2}{|c|}{38.0} & \multicolumn{2}{|c|}{40.5} \\
\hline Smoking habit (\% current smokers) & \multicolumn{2}{|c|}{$17 \cdot 9$} & \multicolumn{2}{|c|}{$3 \cdot 4$} & \multicolumn{2}{|c|}{$18 \cdot 4$} & \multicolumn{2}{|c|}{$6 \cdot 5$} & \multicolumn{2}{|c|}{$12 \cdot 7$} & \multicolumn{2}{|c|}{$16 \cdot 2$} \\
\hline
\end{tabular}

* One subject was not included because of missing data for this analysis. 
Table 2. Energy and fat intake after 2 years of nutritional intervention according to intervention group (Mean values and standard deviations)

\begin{tabular}{|c|c|c|c|c|c|c|}
\hline & \multicolumn{2}{|c|}{ Control (n 197) } & \multicolumn{2}{|c|}{ Virgin olive oil $(n 318)$} & \multicolumn{2}{|c|}{ Tree nuts ( $n$ 259) } \\
\hline & Mean & SD & Mean & SD & Mean & SD \\
\hline \multicolumn{7}{|l|}{ Total energy } \\
\hline $\mathrm{kJ} / \mathrm{d}$ & 8024.5 & $1940 \cdot 5$ & $9702 \cdot 3^{\star \star}$ & $1915 \cdot 4$ & $9780 \cdot 9^{\star \star \star}$ & $1843 \cdot 1$ \\
\hline $\mathrm{kcal} / \mathrm{d}$ & $1917 \cdot 9$ & 463.8 & $2318 \cdot 9^{\star \star}$ & $457 \cdot 8$ & $2337 \cdot 7^{\star \star \star}$ & 440.5 \\
\hline Total fat (\% total energy intake) & $34 \cdot 2$ & $9 \cdot 8$ & $44 \cdot 2^{\star \star \star \star}$ & $9 \cdot 6$ & $44 \cdot 2^{\star \star \star \star}$ & $9 \cdot 3$ \\
\hline SFA (\% total energy intake) & 8.9 & $2 \cdot 0$ & $9 \cdot 0$ & 1.7 & $9 \cdot 1$ & 1.7 \\
\hline MUFA (\% total energy intake) & $19 \cdot 8$ & 4.4 & $23 \cdot 4^{\star \star \star *}$ & $3 \cdot 6$ & $23 \cdot 1^{\star \star \star \star}$ & $3 \cdot 6$ \\
\hline PUFA (\% total energy intake) & $5 \cdot 6$ & $1 \cdot 9$ & $6 \cdot 7^{\star \star \star \star}$ & 1.5 & $7 \cdot 1^{\star \star \star \star}+\dagger$ & 1.0 \\
\hline MUFA:total fat & 0.52 & 0.05 & $0.55^{\star \star \star \star}$ & 0.04 & $0.54^{\star \star \star \star} \dagger$ & 0.04 \\
\hline PUFA:total fat & $0 \cdot 15$ & 0.04 & $0 \cdot 16^{\star}$ & 0.04 & $0 \cdot 17^{\star \star \star \star}+† \dagger$ & 0.02 \\
\hline SFA:total fat & 0.24 & 0.04 & $0 \cdot 21^{\star \star \star \star}$ & 0.04 & $0.21^{\star \star \star \star}$ & 0.04 \\
\hline
\end{tabular}

Mean value was significantly different from that of the control group: ${ }^{\star} P=0.009,{ }^{\star \star} P=0.008,{ }^{\star \star \star} P=0.004,{ }^{\star \star \star \star} P<0.001$.

Mean value was significantly different from that of the virgin olive oil group: $\uparrow P=0.019, \dagger^{\dagger} P=0.001, \dagger \dagger+P<0.001$.

linear models adjusting for age, baseline BMI (continuous), sex, diabetes and smoking habit.

The effects of the polymorphism on changes in anthropometric variables were evaluated with multivariate linear regression models adjusting for relevant variables: age, sex (males as the reference category), baseline BMI, diabetes and smoking habits. For each adiposity index (changes in waist circumference (2nd year waist circumference - baseline waist circumference), body weight (2nd year weight baseline weight) and BMI (2nd year BMI - baseline BMI)) three regression models were fit: the first model analysed the effects of the nutritional intervention and the polymorphism separately on changes in adiposity indexes. The second model included the interaction product-term between the nutritional intervention (olive oil + nuts $v$. control) and the Pro12Ala polymorphism (12Ala carriers $v$. non-carriers) and the third model included dummy variables to consider each possible combination of the genetic variants and the nutritional intervention group simultaneously.

We repeated all these analyses including only diabetic patients.

\section{Results}

Baseline characteristics of the participants, according to the nutritional intervention and the polymorphism, are presented in Table 1. As expected, because of the randomisation, there were no statistically significant differences among the three nutritional groups in any of the biological variables. Most of the PREDIMED subjects, at baseline, were overweight or obese $(91 \%)$ and more than one-third had a diagnosis of type 2 diabetes.

The analysis of macronutrient intake at the beginning of the study and after 2 years of nutritional intervention revealed that the intervention brought about an effective change in the dietary pattern of the subjects with significant differences in the expected direction according to the respective allocated group. These changes were remarkable regarding fat consumption (Table 2). A significantly higher consumption of total fat, monounsaturated and polyunsaturated fat (but not saturated fat) was observed in both Mediterranean diet groups compared with the control group (Table 2). Moreover, the control group had a significantly higher ratio of saturated fat:total fat than those subjects allocated to the Mediterranean diet groups (Table 2).

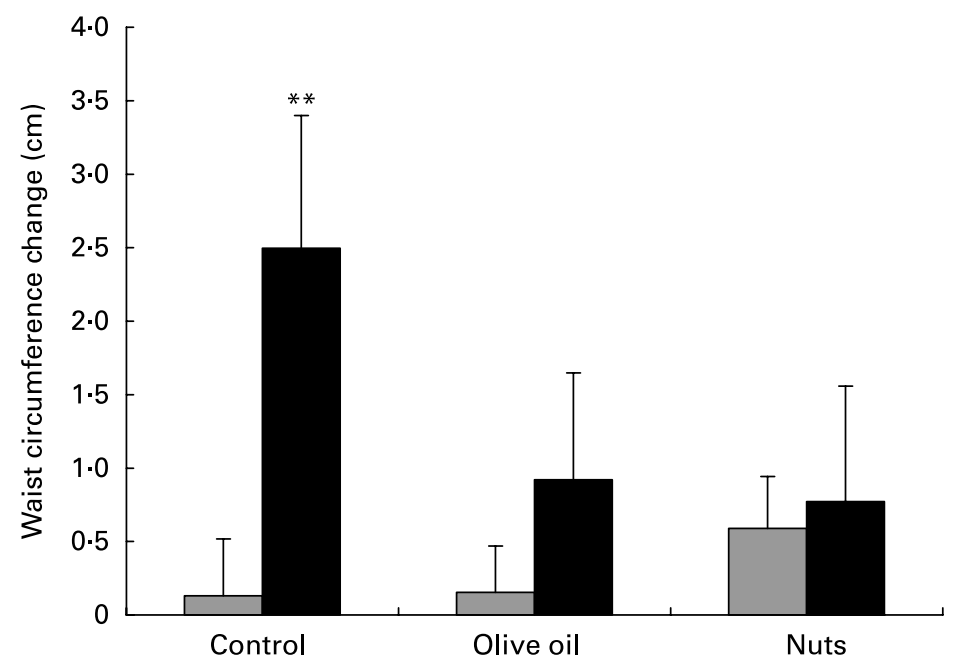

Fig. 1. Waist circumference changes according to the Pro12Ala polymorphism ( $\square$, ProPro; $\mathbf{\square}$, Ala) of the PPAR $y$ gene after 2 years of nutritional intervention in the total population. Data are means, with standard deviation represented by vertical bars. ${ }^{*}$ Mean value was significantly different from that of the non-mutated subjects allocated to the control group $(P=0.011)$. 
To analyse whether the Mediterranean diet had a beneficial effect on adiposity indexes, we first investigated body weight and waist circumference changes depending on the intervention group. Mean body weight changes for the control, olive oil and nuts groups were similar (0.34 (SEM 0.28), 0.33 (SEM 0.22) and 0.87 (SEM 0.21$) \mathrm{kg}$, respectively). The comparison for mean body weight changes was not statistically significant, neither between control and olive oil $(P=0.992)$ nor control and nuts $(P=0 \cdot 131)$. Mean waist circumference changes were also alike in the control, olive oil and nuts groups (0.35 (SEM 0.35), 0.14 (SEM 0.28) and 0.51 (SEM $0 \cdot 26) \mathrm{cm}$, respectively). No differences were found when control and olive oil $(P=0.632)$ or control and nuts $(P=0.711)$ were compared.

The distribution of genotypes for the Pro12Ala of PPAR $\gamma$ gene polymorphism was in Hardy-Weinberg equilibrium in the study groups, being the 12Ala allele frequency 0.07 in each group. Due to the low frequency of $12 \mathrm{Ala}$ of the PPAR $\gamma$ gene, only four out of the 774 subjects were homozygous for the polymorphism (Ala12Ala). Therefore we decided to merge in all the analysis the Ala carriers (both heterozygous and homozygous merged together as a single group, representing $14.5 \%$ of the total population) and to compare them with the non-mutated subjects. Therefore this variable had always $1 \mathrm{df}$.

Adjusted mean body weight changes were 0.56 and $0.92 \mathrm{~kg}$ for ProPro and Ala carriers, respectively. Mean waist changes were $0.30 \mathrm{~cm}$ in non-mutated (ProPro) and $1.28 \mathrm{~cm}$ in mutated subjects (Ala carriers), this difference being statistically significant $(P=0 \cdot 046)$. Moreover, when the three nutritional groups were also considered in the model, we observed that in the control group the 12Ala carriers had a significantly higher $(P=0.011)$ waist circumference increase compared with non-carriers after 2 years of nutritional intervention (Fig. 1). The same tendency was observed when weight changes were analysed, although the differences within control subjects carrying the 12Ala allele $v$. non-mutated subjects were not statistically significant (data not shown). The polymorphism was not associated with differences in waist circumference changes within both Mediterranean diet groups.

To go deeper in our analysis, several multiple linear regression models were fitted in order to find out the model that best predicted the effects of the Mediterranean diet on adiposity indexes depending on the Pro12Ala polymorphism of the PPAR $y$ gene. Table 3 shows the model to predict the effects of the diet (considering the three intervention groups) and the two groups of genetic variants on waist circumference changes (2nd year - baseline), adjusting for sex, age, baseline BMI, diabetes and smoking habit. The obtained results supported the finding of the analysis of covariance (ANCOVA) showing that carriers of the 12Ala allele had a statistically significant increase in waist circumference compared with nonmutated subjects (ProPro) $(P=0 \cdot 046)$. Moreover, we found that subjects with higher baseline BMI were those with the highest waist circumference reduction (adjusted changes: $-0.20 \mathrm{~cm} ; P<0.001)$ after 2 years of nutritional intervention regardless of nutritional intervention and genotype (Table 3 ).

When a $1 \mathrm{df}$ product-term to assess effect modification (interaction) between the nutritional intervention (control (0) $v$. Mediterranean diet groups (1)) and the two groups of genotypes (Ala carriers (1) $v$. non-carriers (0)) on waist circumference changes
Table 3. Multiple regression models for the analysis of the effects of the Pro12Ala polymorphism of the PPAR 2 gene on waist circumference change after 2 years of nutritional intervention

(B coefficients and $95 \%$ confidence intervals)

\begin{tabular}{|c|c|c|c|}
\hline & $\mathrm{B}^{*}$ & $95 \% \mathrm{Cl}$ & $P$ \\
\hline \multicolumn{4}{|c|}{ Considering the polymorphism and nutritional group main effects } \\
\hline Intercept & $7 \cdot 889$ & $2 \cdot 815,12.962$ & 0.002 \\
\hline Age & -0.042 & $-0.094,0.010$ & 0.117 \\
\hline \multicolumn{4}{|l|}{ Sex } \\
\hline Males & 0 & Reference & \\
\hline Females & 0.312 & $-0.565,1.189$ & 0.485 \\
\hline Baseline BMI & -0.199 & $-0.301,-0.096$ & $<0.001$ \\
\hline \multicolumn{4}{|l|}{ Diabetes } \\
\hline No & 0 & Reference & \\
\hline Yes & 0.187 & $-0.519,0.893$ & 0.603 \\
\hline \multicolumn{4}{|l|}{ Nutritional intervention } \\
\hline Control & 0 & Reference & \\
\hline Virgin olive oil & -0.208 & $-1.055,0.639$ & 0.630 \\
\hline Nuts & 0.146 & $-0.741,1.032$ & 0.747 \\
\hline \multicolumn{4}{|l|}{ Pro12Ala polymorphism } \\
\hline ProPro & 0 & Reference & \\
\hline 12Ala allele carriers & 0.980 & $0.017,1.942$ & 0.046 \\
\hline \multicolumn{4}{|l|}{ Smoking habit } \\
\hline Non-smokers & 0 & Reference & \\
\hline Ex-smokers & 0.388 & $-0.609,1.386$ & 0.322 \\
\hline Current smokers & 0.559 & $-0.547,1.664$ & 0.217 \\
\hline \multicolumn{4}{|c|}{$\begin{array}{l}\text { Introducing five dummy variables to include the combinations of the } \\
\text { three nutritional groups and the two genotype groups } \dagger\end{array}$} \\
\hline Intercept & $7 \cdot 965$ & $2 \cdot 892,13.038$ & 0.002 \\
\hline Age & -0.044 & $-0.096,0.008$ & 0.096 \\
\hline \multicolumn{4}{|l|}{ Sex } \\
\hline Males & 0 & Reference & \\
\hline Females & 0.303 & $-0.574,1.179$ & 0.498 \\
\hline Baseline BMI & -0.201 & $-0.304,-0.098$ & $<0.001$ \\
\hline \multicolumn{4}{|l|}{ Diabetes } \\
\hline No & 0 & Reference & \\
\hline Yes & 0.173 & $-0.534,0.879$ & 0.631 \\
\hline \multicolumn{4}{|c|}{ Nutritional intervention and Pro12Ala polymorphism } \\
\hline Control and ProPro & 0 & Reference & \\
\hline Control and Alał & $2 \cdot 366$ & $0.478,4 \cdot 255$ & 0.014 \\
\hline Olive oil and ProPro & 0.025 & $-0.889,0.939$ & 0.957 \\
\hline Olive oil and Alał & 0.790 & $-0.783,2.363$ & 0.324 \\
\hline Nuts and ProPro & 0.460 & $-0.497,1.417$ & 0.346 \\
\hline Nuts and Alał & 0.643 & $-1.051,2.336$ & 0.457 \\
\hline \multicolumn{4}{|l|}{ Smoking habit } \\
\hline Non-smokers & 0 & Reference & \\
\hline Ex-smokers & 0.422 & $-0.577,1.422$ & 0.407 \\
\hline Current smokers & 0.607 & $-0.501,1.714$ & 0.282 \\
\hline
\end{tabular}

* Dependent variable: waist circumference change (2nd year waist circumference baseline waist circumference).

tWhen the interaction was formally tested, the $P$ value for interaction $(2 \mathrm{df}$; three diet groups $\times$ two genotype groups) was $P=0.214$.

$\ddagger$ Homozygous and heterozygous subjects merged together in a single group.

was introduced in the model (data not shown), the $P$ value was not statistically significant $(\mathrm{B}=-1.89 ; P=0.095)$.

Thus, to better analyse the effects of the Mediterranean diet and the polymorphism together, we applied a multiple regression model with five dummy variables to include the combinations of the three nutritional groups and the two groups of genotypes as compared with non-mutated subjects (ProPro genotype) allocated to the control group, who were the single reference category (Table 3 ). This model was adjusted for sex, age, baseline BMI, diabetes and smoking habit and the dependent variable was 2-year waist circumference change (2nd year - baseline). We found that subjects allocated to the control group who also were carriers of the 
PPAR $\gamma$ polymorphism (12Ala) had the highest 2-year waist circumference increase compared with the reference group (adjusted difference $=2.37 \mathrm{~cm} ; \quad P=0.014$ ). In agreement with the ANCOVA results, there were no statistically significant differences within the subjects allocated to the Mediterranean diet groups, independently of the genotype, and the reference category.

Similar models were fit considering as the dependent variables body weight or BMI changes. The results were in line with findings regarding waist circumference, but neither of them reached significance for the product-terms of interaction (data not shown).

Of special interest was the analysis that we performed with the subset of diabetic patients ( $n$ 276) in order to investigate the effects of the Mediterranean diet on adiposity depending on the genotype for the PPAR $\gamma$ within this group. The general linear model showed that the detrimental effect of the 12Ala allele on waist changes was statistically significant $(P<0.001)$ within the subset of diabetic subjects allocated to the control group (Fig. 2), and the magnitude of this effect was higher than in the whole population (Figs. 1 and 2). In diabetic mutated subjects, the Mediterranean diet was able to reduce waist circumference, reversing the negative effect of the 12Ala allele (Fig. 2). As shown in the total population this effect was also observed when analysing body weight changes although it did not reach statistical significance (data not shown).

A statistically significant interaction within diabetic subjects was observed between the nutritional intervention (control (0) $v$. Mediterranean diet groups (1)) and the polymorphism (Ala carriers (1) $v$. non-carriers (0)) in the multiple linear regression model. Ala carriers allocated to the Mediterranean diet groups were predicted to have a statistically significant lower increase in waist circumference compared with control subjects ( $\mathrm{B}=-5.85 ; P=0.003$ ), although the main effect of the polymorphism per se predicted a statistically higher waist circumference change after 2 years of nutritional intervention (B $=0.980 ; P=0.046)$ (Table 4).

The same models fitted among diabetic patients were performed in non-diabetic patients, but they did not reach statistical significance (Table 4).

Regarding these results a three-way interaction assessing genotype $(1 \mathrm{df}$; Ala carriers $v$. non-carriers $) \times$ intervention
( $1 \mathrm{df}$; control $v$. Mediterranean diet groups $) \times$ diabetes $(1 \mathrm{df}$; yes $v$. no) was tested in our regression model for waist circumference change after 2 years of intervention. We obtained a non-statistically significant $P$ value $(\mathrm{B}=-0.66 ; P=0.270)$. In this context the interaction product diabetes $\times$ genotype (1 df) resulted statistically significant within the control group $(P=0 \cdot 012)$ when analysing separately the control and the Mediterranean diet groups (olive oil and nuts merged together).

\section{Discussion}

The excess of adiposity is considered as the main cause of the increased morbidity and mortality by CVD, especially when this excess is localised in the abdominal depots ${ }^{(4)}$. Waist circumference is an excellent marker of abdominal obesity and consequently of CVD risk ${ }^{(4)}$ and mortality ${ }^{(29)}$. Therefore, the reduction of adiposity indexes, such as waist circumference and body weight, would result in an effective prevention for CVD. We have studied the effect of the Pro12Ala polymorphism of the PPAR $\gamma$ gene on 2-year changes in adiposity indexes in a population assigned to a nutritional intervention trial with the Mediterranean diet (the PREDIMED trial), a randomised and controlled study for the prevention of CVD, which allowed us to control not only for established confounding factors such as sex, age and baseline parameters but also for unknown or unmeasured confounders.

First of all, the present results proved the effectiveness of the Mediterranean diet nutritional intervention since the fat intake distribution in the three nutritional groups changed in the expected direction ${ }^{(26)}$. After 2 years, both Mediterranean dietary groups had a significantly higher consumption of total fat compared with the control group and the distribution of fatty acid intake was also very different. The Mediterranean diet groups had a significantly higher consumption of MUFA and PUFA and significantly lower saturated fat consumption, which are important characteristics of the Mediterranean dietary pattern ${ }^{(7)}$.

When we analysed the effects of the nutritional intervention, no differences in changes in waist circumference and weight were found according to the nutritional group. This could be explained because the control subjects recruited for the trial already followed a healthier lifestyle before being

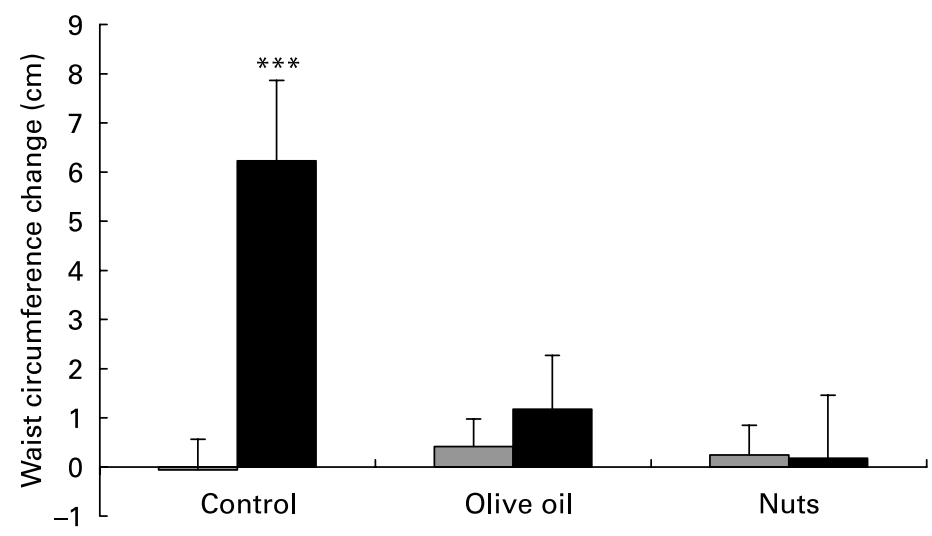

Fig. 2. Waist circumference changes according to the Pro12Ala polymorphism ( $\square$, ProPro; $\mathbf{\square}$, Ala) of the PPAR gene after 2 years of nutritional intervention in diabetic patients. Data are means, with standard deviation represented by vertical bars. ${ }^{\star \star \star}$ Mean value was significantly different from that of the non-mutated subjects allocated to the control group $(P<0.001)$. 
Table 4. Multiple regression models for the analysis of the effects of the Pro12Ala polymorphism of the PPAR 2 gene on waist circumference change in diabetic and non-diabetic patients after 2 years of nutritional intervention

(B coefficients and $95 \%$ confidence intervals)

\begin{tabular}{|c|c|c|c|}
\hline & $\mathrm{B}^{*}$ & $95 \% \mathrm{Cl}$ & $P$ \\
\hline \multicolumn{4}{|c|}{ Diabetic patients } \\
\hline \multirow{2}{*}{\multicolumn{4}{|c|}{$\begin{array}{l}\text { Main effects of the Pro12Ala polymorphism, adjusted for sex (female), age, baseline BMI, interven- } \\
\text { tion and smoking habit }\end{array}$}} \\
\hline & & \\
\hline Non-mutated & 0 & Reference & \\
\hline 12Ala carriers & 0.980 & $0.017,1.943$ & 0.046 \\
\hline \multicolumn{4}{|c|}{ Considering the interaction product-term nutritional intervention $\times$ polymorphism } \\
\hline Intercept & 14.902 & $5 \cdot 876,23.928$ & 0.001 \\
\hline Age & -0.131 & $-0.228,-0.034$ & 0.008 \\
\hline \multicolumn{4}{|l|}{ Sex } \\
\hline Males & 0 & Reference & \\
\hline Females & $0 \cdot 111$ & $-1.379,1.601$ & 0.884 \\
\hline Baseline BMI & -0.227 & $-0.389,-0.065$ & 0.006 \\
\hline \multicolumn{4}{|l|}{ Nutritional intervention } \\
\hline Control & 0 & Reference & \\
\hline Intervention† & 0.396 & $-1.087,1.879$ & 0.600 \\
\hline \multicolumn{4}{|l|}{ Pro12Ala polymorphism } \\
\hline ProPro & 0 & Reference & \\
\hline 12Ala allele carriers & $6 \cdot 272$ & $2 \cdot 842,9 \cdot 702$ & $<0.001$ \\
\hline Intervention $\dagger \times 12$ Ala allele $\ddagger$ & -5.853 & $-9.691,-2.016$ & 0.003 \\
\hline \multicolumn{4}{|l|}{ Smoking habit } \\
\hline Non-smokers & 0 & Reference & \\
\hline Ex-smokers & -0.013 & $-1.638,1.611$ & 0.987 \\
\hline Current smokers & $1 \cdot 126$ & $-0.973,3.226$ & 0.292 \\
\hline \multicolumn{4}{|c|}{ Non-diabetic patients } \\
\hline \multicolumn{4}{|c|}{ Considering the interaction product-term nutritional intervention $\times$ polymorphism } \\
\hline Intercept & 5.491 & $-0.372,11.353$ & 0.066 \\
\hline Age & -0.005 & $-0.067,0.056$ & 0.862 \\
\hline \multicolumn{4}{|l|}{ Sex } \\
\hline Males & 0 & Reference & \\
\hline Females & 0.462 & $-0.620,1.544$ & 0.402 \\
\hline Baseline BMI & -0.199 & $-0.334,-0.064$ & 0.004 \\
\hline \multicolumn{4}{|l|}{ Nutritional intervention } \\
\hline Control & 0 & Reference & \\
\hline Intervention† & 0.133 & $-0.874,1.140$ & 0.795 \\
\hline \multicolumn{4}{|l|}{ Pro12Ala polymorphism } \\
\hline ProPro & 0 & Reference & \\
\hline 12Ala allele carriers & 0.484 & $-1 \cdot 766,2 \cdot 737$ & 0.672 \\
\hline Intervention $\dagger \times 12$ Ala allele $\neq$ & 0.244 & $-2.432,2.920$ & 0.858 \\
\hline \multicolumn{4}{|l|}{ Smoking habit } \\
\hline Non-smokers & 0 & Reference & \\
\hline Ex-smokers & 0.660 & $-0.605,1.925$ & 0.306 \\
\hline Current smokers & 0.310 & $-0.986,1.606$ & 0.639 \\
\hline
\end{tabular}

* Dependent variable: waist circumference change (2nd year waist circumference - baseline waist circumference).

$\dagger$ Intervention refers to the comparison between olive oil and nuts groups $v$. control group (1 df). The two intervention groups (olive oil and nuts) were merged together.

$\ddagger 12$ Ala allele: comparison between 12Ala carriers (homozygotes and heterozygotes merged together) and non-carriers (ProPro genotype) (1 df).

included in the present study. This fact may justify the small differences in weight and waist changes between the Mediterranean groups and the control group after 2 years of intervention.

Our main objective was to analyse the effects of a Mediterranean dietary pattern depending on the Pro12Ala polymorphism of the PPAR $\gamma$ gene. We found a minor 12Ala allele frequency of 0.07 , lower than values reported in Spanish subjects $(0 \cdot 13)^{(28)}$ but similar to those obtained in European populations $^{(30)}$.

The analysis of the genotype variants on changes on adiposity indexes, adjusted for the nutritional intervention, revealed that the 12 Ala allele was associated with statistically significant higher increase in waist circumferences $(P=0 \cdot 046)$.
It also showed higher, but not significant, body weight changes and BMI after 2 years of nutritional intervention. The majority of the studies analysing the effects of the polymorphism on adiposity indexes are directed to BMI, but there are few studies analysing the effects of the polymorphism on waist circumference. Similarly to our findings, Pihlajamaki et al. reported a significant association of waist circumference and the polymorphism in a healthy Finnish population $^{(31)}$.

When considering the nutritional intervention we observed that the negative effect of the Ala allele on waist changes was only present in the control group $(P=0.011)$ and it was highly attenuated in the two Mediterranean diet groups (Fig. 1). It seems that the Mediterranean diet reversed the 
detrimental effect that the 12Ala minor allele appears to have on waist circumference. One plausible hypothesis that could partly explained this finding is that PPAR $\gamma$ gene is known to be activated by fatty acids ${ }^{(25)}$ and, as stated before, the Mediterranean diet consists of a high consumption of monounsaturated (olive oil) and polyunsaturated fat (nuts).

The interaction between the Mediterranean diet and the Pro12Ala polymorphism of the PPAR $\gamma$ gene on adiposity presented was not statistically significant $(\mathrm{B}=-1.863$; $P=0.095)$ although Robitaille et al. reported a Pro12Ala $\times$ diet interaction on waist circumference: ProPro subjects had significantly higher waist circumference when higher levels of total fat $(P=0.007)$ or saturated fat $(P=0.002)$ were consumed $^{(2)}$.

Due to the potential role that the Pro12Ala polymorphism of the PPAR $\gamma$ gene seemed to have on type 2 diabetes $^{(22,32)}$, we performed a specific analysis on diabetic patients. This analysis revealed that the detrimental effect that the polymorphism appeared to have on waist circumference and weight changes was more relevant among these patients than in the total study population (Fig. 2). Moreover, the reversing effect of the nutritional intervention was also higher in diabetic 12Ala carriers allocated to the two Mediterranean diet groups. The interaction product-term, intervention $\times 12 \mathrm{Ala}$, was statistically significant, confirming the protective effect of the Mediterranean diet against higher waist circumference, especially in 12Ala carriers. Some authors have reported the beneficial effects of the Mediterranean diet on diabetes ${ }^{(8,33,34)}$ and glycaemic control $^{(35)}$. Likewise, there are also studies analysing the effects of the polymorphism and dietary compounds on adiposity indexes in diabetic patients. In agreement with our findings, a higher visceral fat deposition on individuals carrying the 12Ala allele and with a low polyunsaturated fat intake was reported $^{(23)}$.

Following the present results, it seems that the negative effect of the 12Ala allele in the total population could be mostly attributed to diabetic patients. Moreover, we observed that this effect was only attenuated when these patients followed a Mediterranean dietary pattern. This attenuation may be partly explained by the fact that fatty acids (high intake of PUFA and MUFA in this dietary pattern) are activating the PPAR $\gamma$ protein and could potentially modify the action of the Pro12Ala substitution on the receptor activity, especially in the presence of diabetes ${ }^{(18,23,25)}$.

The present study has several strengths, such as its design, which is able to provide first-level scientific evidence ${ }^{(36)}$, as we work in real-life conditions (home-prepared foods). But the study also has some limitations. The first was to ensure participants' compliance with the aid of continuous dietary instructions. In fact, we could observe that the dietary pattern (especially fat distribution) was significantly different between the Mediterranean diet groups and the control group after 2 years of intervention (Table 2). Another limitation of the statistical procedure is that multiple comparisons were performed in order to examine the contribution of the three nutritional groups and the different genotypes, but the differences remained statistically significant even after the Bonferroni correction.

In summary, the present study shows that Mediterraneanstyle diets seemed to be able to reduce 2-year waist circumference enlargement in a high-cardiovascular risk population, reversing the negative effect that carrying the 12Ala allele of the PPAR $\gamma$ gene appeared to have. The beneficial effect of this dietary pattern seemed to be more important among type 2 diabetic subjects.

\section{Acknowledgements}

C. R. has a predoctoral fellowship from IBERCAJA.

We would also like to thank all the participants and members of the PREDIMED project.

The authors acknowledge the following sources of support: Department of Health of the Navarra Government, Linea Especial sobre Nutrición, Obesidad y Salud (LE 97), RETICS Scheme funded by the Spanish Ministry of Health (PREDIMED Project, reference RD 06/0045/0000). CIBERobn is an initiative of ISCIII (CB06/03/1017).

C. R. carried out the experimental procedures, the analysis and interpretation of the data, and drafted the manuscript. A. M. participated in the design of the study, contributed to the analysis and interpretation of the data, and helped to draft the manuscript. M. A. M.-G. helped with the statistical analysis and helped to draft the manuscript. J. A. M. helped with the interpretation of the data and helped to draft the manuscript. M. A. M.-G., D. C. and J. M. S. participated in the initiation and design of the study and in the recruitment of the subjects. All authors read and approved the final version of the manuscript.

The authors have no conflicts of interest to declare.

\section{References}

1. Estruch R, Martinez-Gonzalez MA, Corella D, et al. (2006) Effects of a Mediterranean-style diet on cardiovascular risk factors: a randomized trial. Ann Intern Med 145, 1-11.

2. Robitaille J, Perusse L, Bouchard C, et al. (2007) Genes, fat intake, and cardiovascular disease risk factors in the Quebec Family Study. Obesity (Silver Spring) 15, 2336-2347.

3. Ordovas JM (2006) Genetic interactions with diet influence the risk of cardiovascular disease. Am J Clin Nutr 83, 443S-446S.

4. Despres JP (2006) Intra-abdominal obesity: an untreated risk factor for type 2 diabetes and cardiovascular disease. $J$ Endocrinol Invest 29, 77-82.

5. Keys A \& Grande F (1957) Role of dietary fat in human nutrition. III. Diet and the epidemiology of coronary heart disease. Am J Public Health Nations Health 47, 1520-1530.

6. Martinez-Gonzalez MA \& Sanchez-Villegas A (2004) The emerging role of Mediterranean diets in cardiovascular epidemiology: monounsaturated fats, olive oil, red wine or the whole pattern? Eur J Epidemiol 19, 9-13.

7. Trichopoulou A (2004) Traditional Mediterranean diet and longevity in the elderly: a review. Public Health Nutr 7, 943-947.

8. Schroder H (2007) Protective mechanisms of the Mediterranean diet in obesity and type 2 diabetes. J Nutr Biochem 18, 149-160.

9. Fernandez-Jarne E, Martinez-Losa E, Prado-Santamaria M, et al. (2002) Risk of first non-fatal myocardial infarction negatively associated with olive oil consumption: a case-control study in Spain. Int J Epidemiol 31, 474-480.

10. Martinez-Gonzalez MA, Fernandez-Jarne E, Serrano-Martinez M, et al. (2004) Development of a short dietary intake questionnaire for the quantitative estimation of adherence to a 
cardioprotective Mediterranean diet. Eur J Clin Nutr 58, $1550-1552$.

11. Albert CM, Gaziano JM, Willett WC, et al. (2002) Nut consumption and decreased risk of sudden cardiac death in the Physicians' Health Study. Arch Intern Med 162, 1382-1387.

12. Hu FB, Stampfer MJ, Manson JE, et al. (1998) Frequent nut consumption and risk of coronary heart disease in women: prospective cohort study. BMJ 317, 1341-1345.

13. Sabate J \& Fraser GE (1994) Nuts: a new protective food against coronary heart disease. Curr Opin Lipidol 5, 11-16.

14. Luan J, Browne PO, Harding AH, et al. (2001) Evidence for gene-nutrient interaction at the PPAR $\gamma$ locus. Diabetes 50, 686-689.

15. Memisoglu A, Hu FB, Hankinson SE, et al. (2003) Interaction between a peroxisome proliferator-activated receptor $\gamma$ gene polymorphism and dietary fat intake in relation to body mass. Hum Mol Genet 12, 2923-2929.

16. Nieters A, Becker N \& Linseisen J (2002) Polymorphisms in candidate obesity genes and their interaction with dietary intake of $n-6$ polyunsaturated fatty acids affect obesity risk in a sub-sample of the EPIC-Heidelberg cohort. Eur J Nutr 41, $210-221$.

17. Ochoa MC, Razquin C, Martinez-Gonzalez MA, et al. (2008) Role of PPARG2 polymorphims in body weight regulation. Future Lipidol 3, 31-41.

18. Deeb SS, Fajas L, Nemoto M, et al. (1998) A Pro12Ala substitution in PPAR $\gamma 2$ associated with decreased receptor activity, lower body mass index and improved insulin sensitivity. Nat Genet 20, 284-287.

19. Ek J, Urhammer SA, Sorensen TI, et al. (1999) Homozygosity of the Pro12Ala variant of the peroxisome proliferation-activated receptor- $\gamma 2$ (PPAR- $\gamma 2$ ): divergent modulating effects on body mass index in obese and lean Caucasian men. Diabetologia 42, 892-895.

20. Masud S \& Ye S (2003) Effect of the peroxisome proliferator activated receptor $\gamma$ gene Pro12Ala variant on body mass index: a meta-analysis. J Med Genet 40, 773-780.

21. Tok EC, Ertunc D, Bilgin O, et al. (2006) PPAR- $\gamma 2$ Pro12Ala polymorphism is associated with weight gain in women with gestational diabetes mellitus. Eur J Obstet Gynecol Reprod Biol 129, 25-30.

22. Tonjes A \& Stumvoll M (2007) The role of the Pro12Ala polymorphism in peroxisome proliferator-activated receptor $\gamma$ in diabetes risk. Curr Opin Clin Nutr Metab Care 10, 410-414.

23. Franks PW, Jablonski KA, Delahanty L, et al. (2007) The Pro12Ala variant at the peroxisome proliferator-activated receptor $\gamma$ gene and change in obesity-related traits in the Diabetes Prevention Program. Diabetologia 50, 2451-2460.

24. Joost HG, Gibney MJ, Cashman KD, et al. (2007) Personalised nutrition: status and perspectives. Br J Nutr 98, 26-31.

25. Xu HE, Lambert MH, Montana VG, et al. (1999) Molecular recognition of fatty acids by peroxisome proliferator-activated receptors. Mol Cell 3, 397-403.

26. Zazpe I, Sanchez-Tainta A, Estruch R, et al. (2008) A large randomized individual and group intervention conducted by registered dietitians increased adherence to Mediterranean-type diets: the PREDIMED study. $J$ Am Diet Assoc 108, 1134-1145.

27. Martin-Moreno JM, Boyle P, Gorgojo L, et al. (1993) Development and validation of a food frequency questionnaire in Spain. Int J Epidemiol 22, 512-519.

28. Ochoa MC, Marti A, Azcona C, et al. (2004) Gene-gene interaction between PPAR $\gamma 2$ and ADR $\beta 3$ increases obesity risk in children and adolescents. Int J Obes Relat Metab Disord 28 Suppl. 3, S37-S41.

29. Pischon T, Boeing H, Hoffmann K, et al. (2008) General and abdominal adiposity and risk of death in Europe. $N$ Engl $J$ Med 359, 2105-2120.

30. Lagou V, Scott RA, Manios Y, et al. (2008) Impact of peroxisome proliferator-activated receptors $\gamma$ and $\delta$ on adiposity in toddlers and preschoolers in the GENESIS Study. Obesity (Silver Spring) 16, 913-918.

31. Pihlajamaki J, Vanhala M, Vanhala P, et al. (2004) The Pro12Ala polymorphism of the PPAR 2 gene regulates weight from birth to adulthood. Obes Res 12, 187-190.

32. Ghoussaini M, Meyre D, Lobbens S, et al. (2005) Implication of the Pro12Ala polymorphism of the PPAR- $\gamma 2$ gene in type 2 diabetes and obesity in the French population. BMC Med Genet 6, 11 .

33. Biesalski HK (2004) Diabetes preventive components in the Mediterranean diet. Eur J Nutr 43, Suppl. 1, I/26-I/30.

34. Martinez-Gonzalez MA, de la Fuente-Arrillaga C, NunezCordoba JM, et al. (2008) Adherence to Mediterranean diet and risk of developing diabetes: prospective cohort study. BMJ 336, 1348-1351.

35. Shai I, Schwarzfuchs D, Henkin Y, et al. (2008) Weight loss with a low-carbohydrate. Mediterranean, or low-fat diet. $N$ Engl J Med 359, 229-241.

36. Woolf SH, Battista RN, Anderson GM, et al. (1990) Assessing the clinical effectiveness of preventive maneuvers: analytic principles and systematic methods in reviewing evidence and developing clinical practice recommendations. A report by the Canadian Task Force on the Periodic Health Examination. J Clin Epidemiol 43, 891-905. 